\title{
Vaginal Cancer pT1 TNM Finding v7
}

National Cancer Institute

\section{Source}

National Cancer Institute. Vaginal Cancer pT1 TNM Finding v7. NCI Thesaurus. Code C89462.

Vaginal cancer with a tumor confined to vagina. (from AJCC 7th Ed.) 